\title{
Howard Malmstadt: an inspiration
}

The following article appeared in 'Analytical Chemistry', Vol.60, No. 2. Honouring, as it does, one of 'Journal of Automatic Chemistry's' editorial advisers, the editor felt it important to reprint it. The editor and publisher gratefully acknowledge the permission of the American Chemical Society to reproduce the article.

At the annual meeting of the Federation of Analytical Chemistry and Spectroscopy Societies (FACSS), which took place in Detroit, 4 to 9 October 1987, Howard V. Malmstadt was doubly honoured. Malmstadt, professor emeritus at the University of Illinois and provost and senior vice-president at the Pacific and Asia Christian University, accepted the 1987 ANACHEM Award. In addition, more than 50 chemists, all academic progeny of Malmstadt, contributed some 150 technical papers to the conference.

The ANACHEM Award, which is given annually by the Association of Analytical Chemists, honours Malmstadt's outstanding contributions to analytical research and education. The technical presentations by Malmstadt's former students (and their students) convincingly demonstrated the wide-ranging influence and importance of the man in both areas.

Howard Malmstadt was born in Marionette, Wisconsin, USA, in 1922. He earned his bachelor's degree at the University of Wisconsin in 1943. During a subsequent three-year hitch in the Navy, he studied electronics at Princeton and at the Massachusetts Institute of Technology and served as a radar officer in the Pacific. After the war he returned to the University of Wisconsin, where he obtained his M.S. (1948) and Ph.D. (1950) degrees in analytical chemistry. In 1951 Malmstadt began a long tenure at the University of Illinois, during which he taught, performed research, and authored or coauthored more than 150 technical articles and 10 books. He retired from Illinois in the early 1980s and assumed his current position at the Pacific and Asia Christian University in Kailua-kona, Hawaii.

During his years at the University of Illinois, Malmstadt earned a reputation as an inspirational force in the analytical community. Gary Hieftje, an early student of Malmstadt's, now at Indiana University, recently reflected: 'He [Malmstadt] emphasized setting high goals. He would urge his students, by example, to set up standards or ideal characteristics that they would like an instrument to possess. He presented an ideal framework for academic growth. And there is tremendous success among his former students'.

Jim Winefordner, the first of Malmstadt's students to enter academia, and now at the University of Florida, echoed Hietje: 'Possibly he [Malmstadt] produced more

(C) 1988 American Chemical Society.
Ph.D.s that pursued academic careers than did any other professor. I think it was something like 20. In terms of scientific ability, he was brilliant. He always had good suggestions, even though he covered a wide swath of projects'. Hieftje concurred: 'His students studied everthing and went in every direction in analytical chemistry'.

Chris Enke, now at Michigan State, has collaborated with Malmstadt on many projects. Enke recently stated, 'Instead of just speaking of principles and ideals, Howard has lived them'. If one area stands out as being strongly advocated and advanced by Malmstadt, it is electronics. He was an innovator and a leader in the development of modular electronic instruments, and he developed a popular and influential course in electronics for scientists. Stan Crouch, another early student, now at Michigan State, summed it up in this way: 'He [Malmstadt] introduced electronics to chemists. He had the vision to see that chemists would be using electronic tools. It is now taken for granted - thanks to Malmstadt - that an analytical chemist will know electronics'. Malmstadt's interest in electronics resulted in the 1962 book, Electronics for Scientists, coauthored by Enke and E. C. Toren, Jr., and the 1981 book, Electronics and Instrumentation for Scientists, coauthored by Enke and Crouch.

Malmstadt is also known for his efforts in the area of kinetic methods. 'He promoted and fostered these methods', said Crouch. Another area that has benefited from Malmstadt's influence is spectroscopy. 'People forget the spectroscopy part', opined Crouch, 'I am creating a spectroscopy text that owes very much to Howard Malmstadt and his course in spectroscopy [that is, the one he developed at the University of Illinois]'.

Malmstadt's professional achievements and past honours are many. He is a former Guggenheim Fellow and was the chairman of the ACS Division of Analytical Chemistry. $\mathrm{He}$ has been on the advisory boards of the National Science Foundation, the National Institutes of Health, the National Research Council, and various scientific journals. He has served as a consultant for US industries and the United Nations and has been a visiting professor or guest lecturer at universities and scientific societies in the USA, UK, Australia, Brazil, Singapore, India, Japan, and China.

Malmstadt's many awards include the following: the Instrument Society of America Award, the ACS Awards in Analytical Chemistry and Chemical Instrumentation, the Pittsburgh Conference Outstanding Chemist Award, the Fulbright-Hay Distinguished Professor Award, the Isco Award for Contributions in Biochemical Instrumentation, and the ACS Division of Analytical Chemistry Excellence in Teaching Award.

In bringing together so many academic relations in one 
The Malmstadt family tree of Ph.D. students who entered the graduate teaching profession, and their students who entered the graduate teaching profession, and so on. Each school cited is either the school at which the person now teaches or the last school at which the person taught before moving on to other pursuits. Postdoctoral associates, undergraduate associates, and nonteaching descendants are omitted. The compilation was made by Paul Beckwith, Dave Coleman, Stan Crouch, Scott Goode, Alex Scheeline, Jim Winefordner, and others.

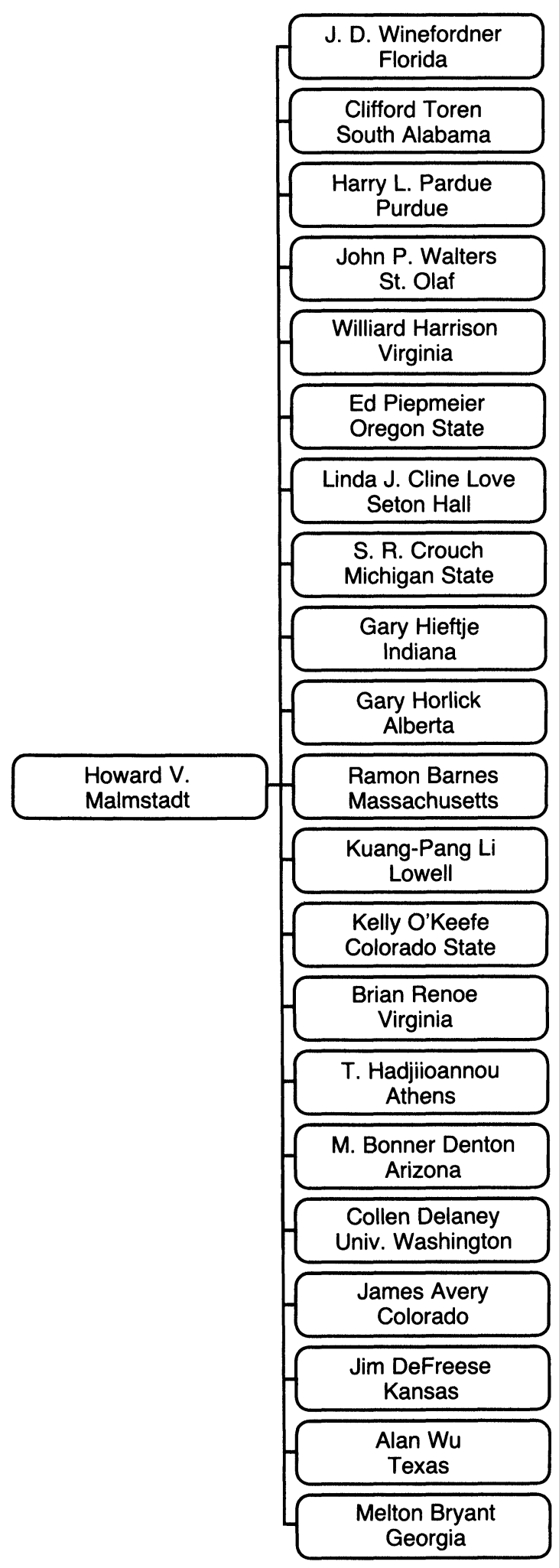

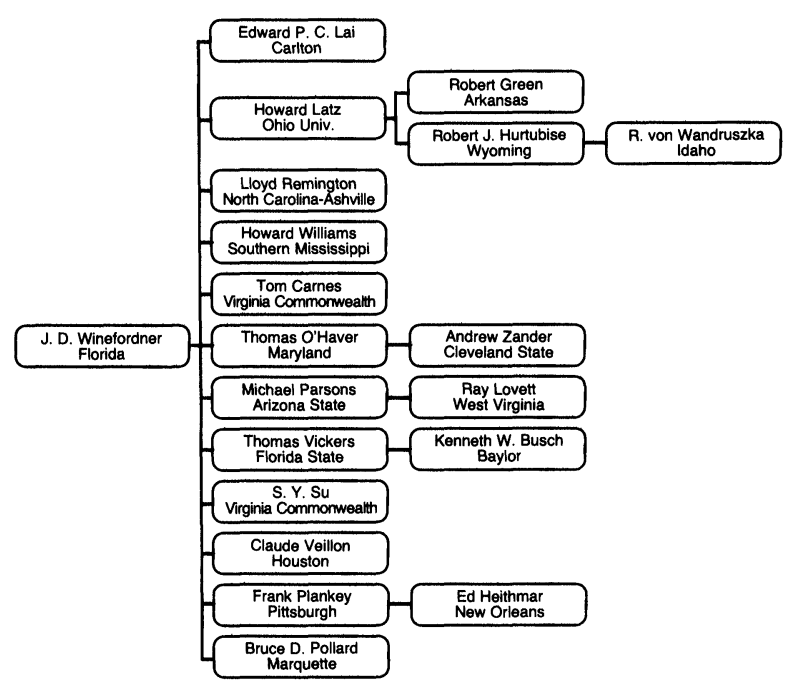
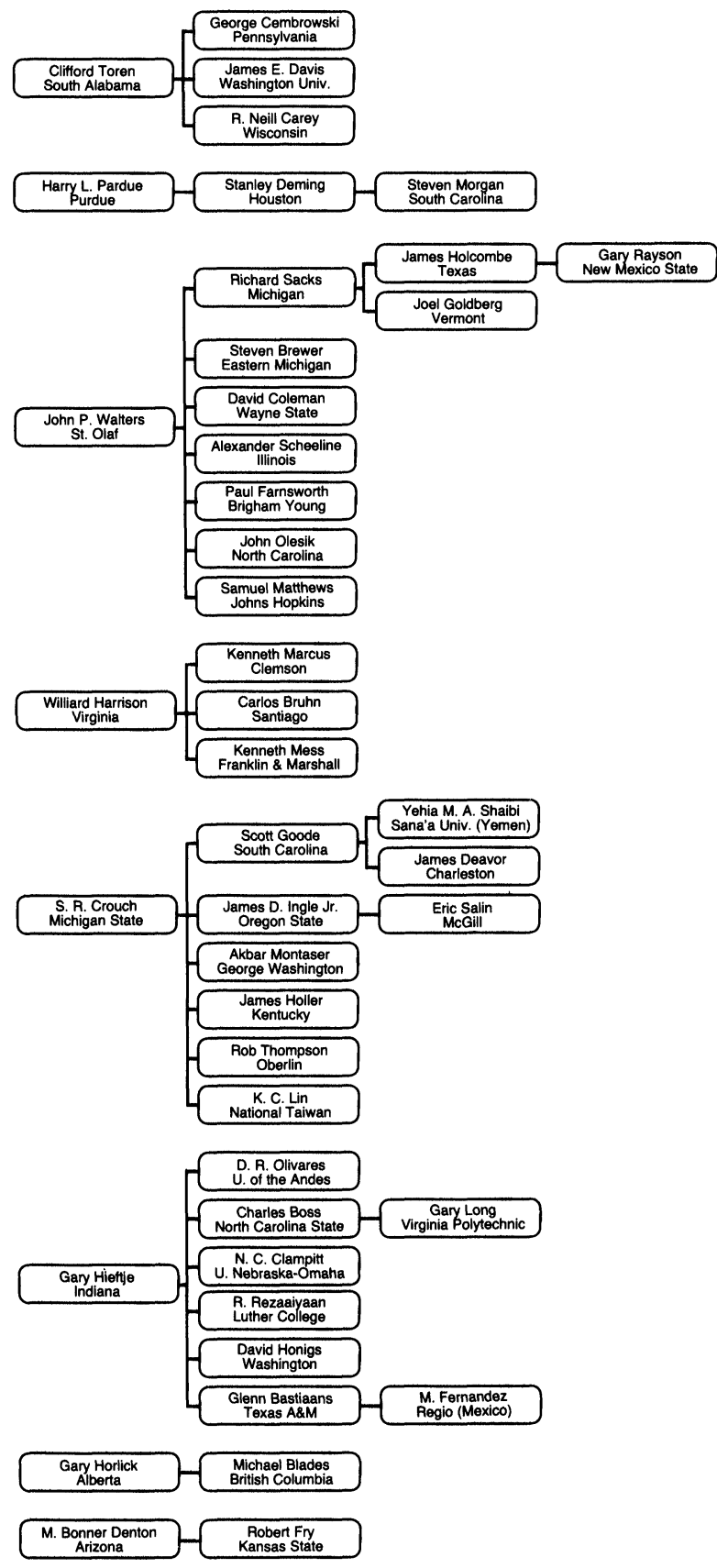
place, the FACSS conference became not just a tribute to the accomplishments of Howard Malmstadt, but also a celebration of the man's spirit. Many of the direct descendants shown in the family-tree, as well as many professional colleagues who have worked with Malmstadt through the years, attended the conference. As acquaintanceships were renewed and old times recalled, the participants shared in the themes of respect and enthusiasm for Malmstadt and his work.

The programme also featured three half-day symposia, each of which was conducted by former students and colleagues of Malmstadt. These symposia, which explored analytical trends and issues of wider scope, were as follows:

'Emerging concepts in instrumentation and education, 'New concepts in spectrochemical analysis', and 'Advances in biotechnological and clinical methodology'.

Malmstadt closed the first symposium with an address entitled 'Technology, education, and communities in need'. In this moving oration, he explored profound issues of chemistry in a social context, drawing on his own appropriate experience. Malmstadt envisioned an academic curriculum that would recognize the needs of communities and provide a framework for satisfying those needs through the course of academic study. In this curriculum, the main objectives of education would be ever present, as problems involving energy, the environment, health, sanitation, and engineering would be dealt with literally. Problems would be identified, the skills required to solve them would be determined, and students would be trained appropriately. Students would work in the field so that their experience would result in a mix of the practical and empirical aspects of problem solving together with the ideal and theoretical aspects.

In his role as a teaching professor, Howard Malmstadt insisted that his students develop and maintain a broad perspective on their discipline. As Gary Hieftje put it, ' $\mathrm{He}$ taught that students should not lose sight of their heritage, that is, the chemistry'. Malmstadt's remarks at the FACSS conference revealed an insistence on an even broader perspective. He now calls upon chemistry students not only to be aware of the wide base of knowledge and the history that surround their work, but also to recognize the responsibilities and possibilities inherent in the relationship between the science and society.

At the Pacific and Asia Christian University, Howard Malmstadt now contributes his knowledge and talents to a programme that is meant to help people living in the Pacific Basin area. He has come full circle since that time, some 40 years ago, when he served as a radar officer in the Pacific theatre and was just starting his career in science. In the intervening years, Malmstadt has worked with countless young scientists, instilling in them good values while pointing them in the direction of good science. This man of patience and brilliance and vision has been, and continues to be, an inspiration.

\section{EDITOR'S NOTE}

Howard Malmstadt is certainly unique in analytical chemistry, but most of all he is quick also to recognize the value of work carried out by other groups. When he visited us at the Laboratory of the Government Chemist in the early 1970s, everyone was impressed by the work he had achieved, particularly in the education of chemists in automation, especially electronics training. Howard had made it simple, and by giving a 'hands-on' approach was able to get chemists confident with the new facilities available. But in his own style, Professor Malmstadt was quick to see the value of the work done at LGG, particularly with respect to sample handling and preparation. On a visit to the USA, I remember being introduced to Howard's group at the University of Urbana-Champaign and was very flattered by his comments on the work done by LGC. Before I could get over this I was almost taken aback by the confidence of this group, who after only five minutes or so of introduction were throwing questions at this lecturer. They were keen to know more details about the work I was describing.

Howard's training had made the group very enthusiastic and also keen to see how other people's work could be used in their own environment. Howard and all of his group were keen to recognize the reality of analysis and to deal with real-world sampling situations.

Howard was also very instrumental in helping me get the Journal off the ground. A quick look at the membership of the editorial board will show this. I remember that he told me it will take a long time for people in America to recognize the value of automation rather than simply computerization. By his enthusiasm and help, we have persevered and we take $J A C$ into the next decade as a well-respected journal.

Thank you Howard for your help and encouragement. Long may we continue to have your valued support.

\section{Peter Stockwell}




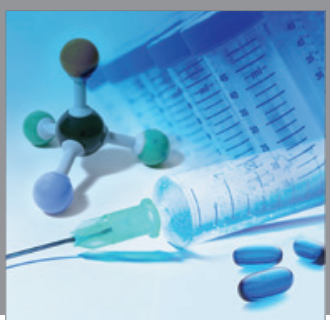

International Journal of

Medicinal Chemistry

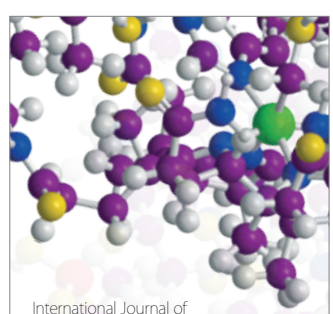

Carbohydrate Chemistry

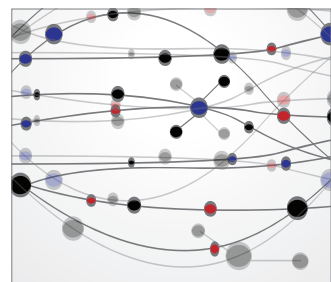

The Scientific World Journal
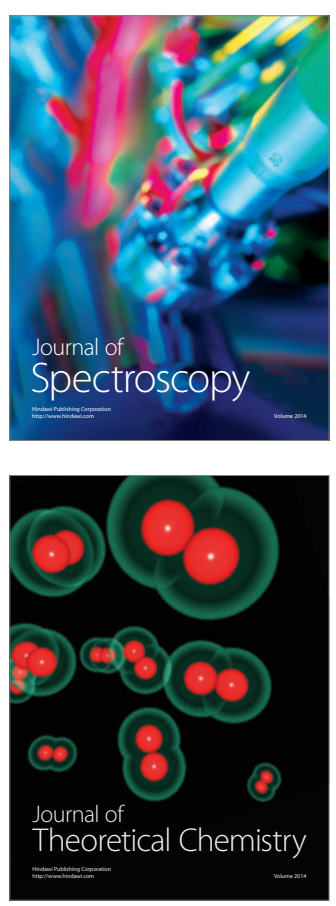
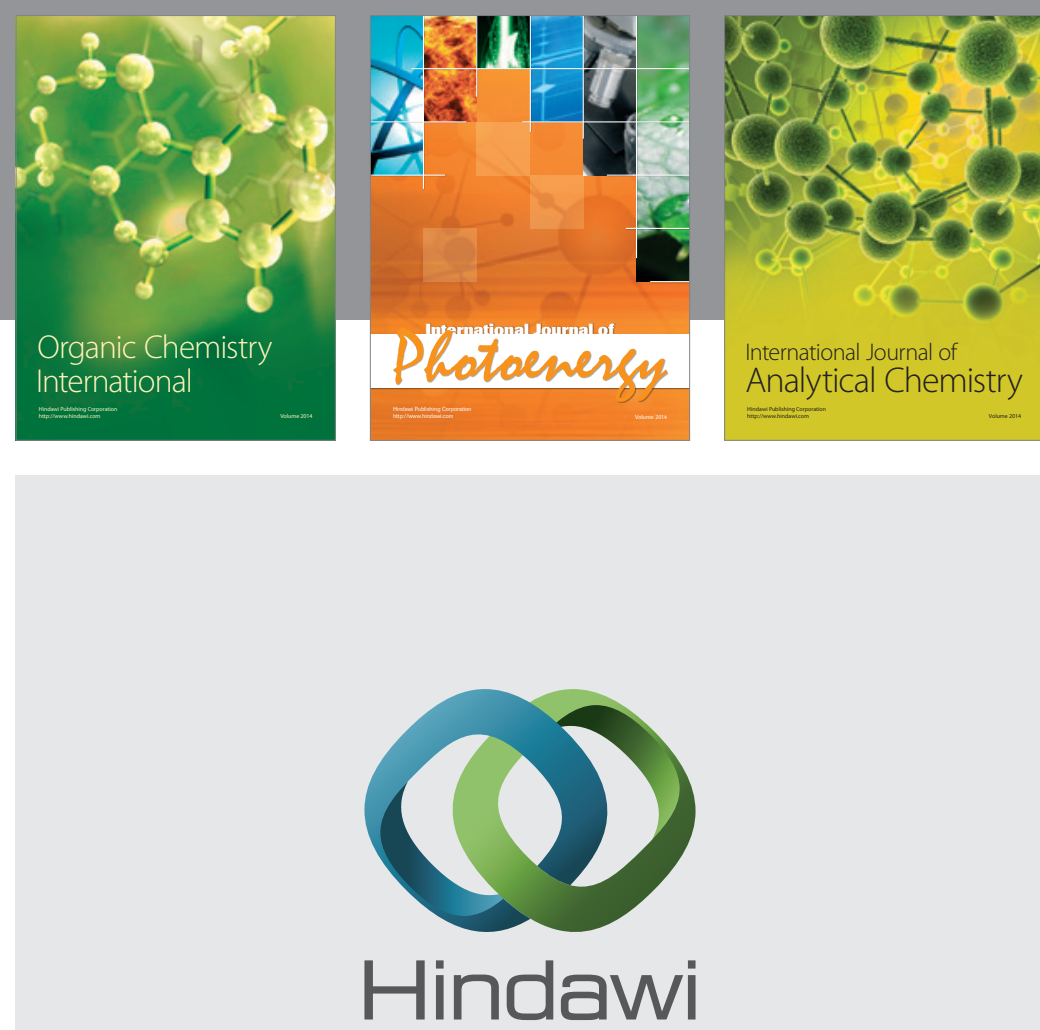

Submit your manuscripts at

http://www.hindawi.com
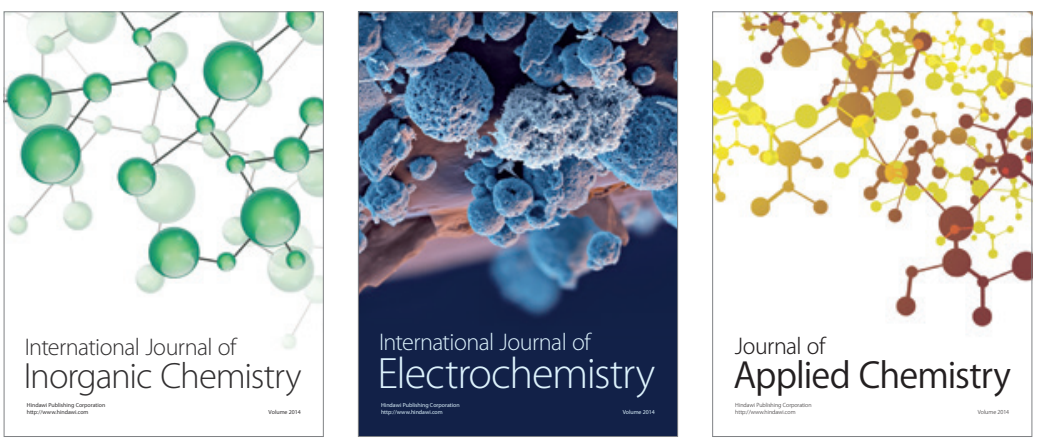

Journal of

Applied Chemistry
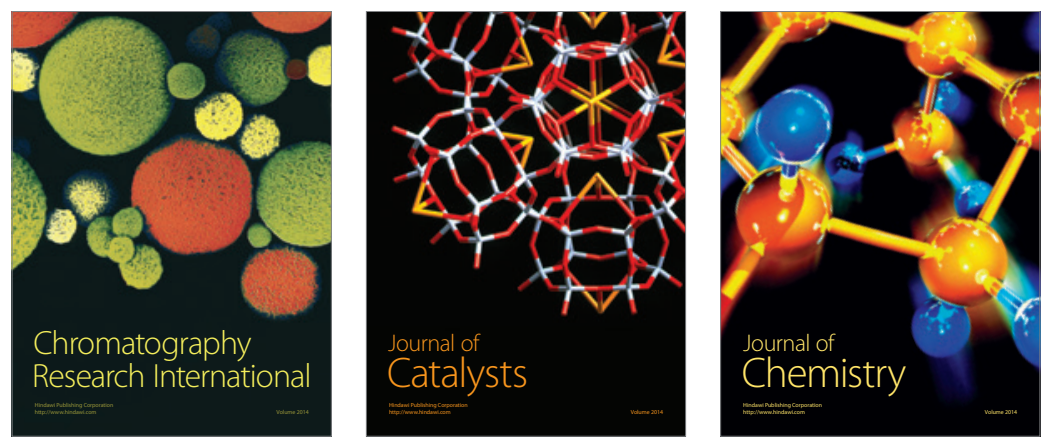
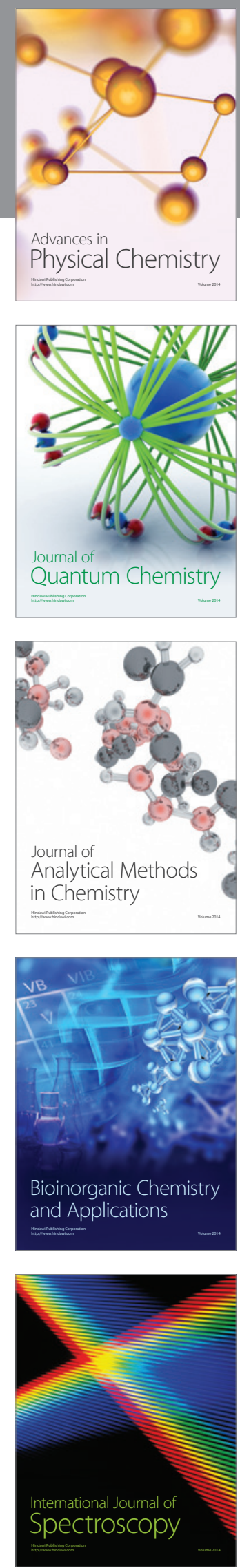